\title{
- Leptospirose: aspectos de saúde animal e de saúde pública
}

\section{- Leptospirosis: animal and public bealth aspects}

\author{
Helio Langoni-CRMV-SP $n^{0} 1912$ \\ Professor Adjunto da Disciplina de Zoonoses \\ Departamento de Higiene Veterinária e Saúde Pública, \\ Faculdade de Medicina Veterinária e Zootecnia, UNESP
}

\author{
Faculdade de Medicina \\ Veterinária e Zootecnia \\ Universidade Estadual \\ Paulista"Julio de Mesquita \\ Filho" UNESP - Botucatu \\ Distrito de Rubião Jr., s/n \\ 18.618-000 - Botucatu - SP \\ E-mail: \\ helio.langoni@mailcity.com
}

\section{RESUMO}

A leptospirose é uma doença de curso agudo à crônico, de caráter zoonótico, afetando diversas espécies animais domésticas e silvestres, inclusive animais pecilotérmicos. As espiroquetas do gênero Leptospira constituem o agente etiológico, sendo encontradas também distribuídas no meio ambiente, mantendo-se em vida saprofítica. É importante problema de saúde pública, relacionado principalmente a características sócio-econômicas, a enchentes, e com aspectos ocupacionais nos indivíduos que trabalham em abatedouros, nas redes de água e esgoto, e em atividades agropecuárias. $\mathrm{O}$ artigo traz informações sobre os agentes envolvidos, incluindo nova classificação, aspectos epidemiológicos referentes às diferentes espécies susceptíveis, com a prevalência da enfermidade. São apresentados ainda os aspectos de patologia, diagnóstico e clínica, bem como de sua profilaxia.

Unitermos: Leptospirose, Saúde animal, Saúde pública

\section{Introdução e Etiologia}

O gênero leptospira era dividido em duas espécies: Leptospira interrogans, que englobava um grande número de variedades patogênicas, e Leptospira biflexa, variedades de comportamento saprófita. Esta divisão baseava-se em critérios estritamente relacionados a reações sorológicas mais ou menos específicas, que forneciam os sorogrupos e sorovares de leptospiras patogênicas e saprófitas. Entretanto, em 1992, o Subcomitê em Taxonomia da Leptospira propôs a divisão da Leptospira interrogans em seis espécies, L.borgpetersenii, L.interrogans, L.noguchii, L.santarosai, L.weilii, L.kirschneri, baseando-se em critérios de diferenciação molecular entre os diversos sorovares (QUIIN et al., 1994).

O Grupo de Genética Molecular de Leptospiras, do Instituto Pasteur de Paris, utilizando o método de hidroxiapatita no estudo da relação entre o DNA dos di- versos sorovares de leptospiras, propõe um modelo de classificação em espécies genômicas ou genomespécies, incluindo às novas espécies citadas acima, outras onze, totalizando três gêneros (Leptospira, Turneria e Leptonema) e 301 sorovares (Tabela 1), segundo BARANTON (1998).

As leptospiras são bastante sensíveis à luz solar direta, aos desinfetantes comuns e aos anti-sépticos. O período de sobrevida das leptospiras patogênicas na água varia segundo a temperatura, o $\mathrm{pH}$, a salinidade e o grau de poluição. Sua multiplicação é ótima em $\mathrm{pH}$ compreendido entre 7,2 a 7,4. Experimentalmente já foi constatada persistência de leptospiras viáveis em água por até 180 dias. O sorovar icterohaemorrhagiae morre em $10 \mathrm{mi}-$ nutos à temperatura de $56^{\circ} \mathrm{C}$ e em 10 segundos quando a $100^{\circ} \mathrm{C}$. Sobrevive ao frio e mesmo ao congelamento $\left(100\right.$ dias a $\left.-20^{\circ} \mathrm{C}\right)$. Pode ser liofilizada e é muito sensí- 
Tabela 1 - Gênero e genomespécie de Leptospiraceae, indicando o sorovar e cepa padrão, e número total de sorovares por genomespécie.

\begin{tabular}{|l|l|l|c|}
\hline Gênero e Genomespécie & Sorovar padrão & Cepa padrão & Nosorovares \\
\hline Leptospira interrogans & Icterohaemorrhagiae & RGA & 91 \\
Leptospira kirshneri & Cynopteri & 3522 C & 29 \\
Leptospira noguchii & Panama & CZ214 & 20 \\
Leptospira santarosai & Shermani & $1342 \mathrm{~K}$ & 65 \\
Leptospira borgpetersenii & Javanica & Veldrat Batavia 46 & 47 \\
Leptospira weilii & Ranarum & CDC & 15 \\
Leptospira wolbachii & Codice & 10 & 2 \\
Leptospira inadai & Lyme & Veldrat Semarang 173 & 10 \\
Leptospira meyeri & Semaranga & Patoc I & 5 \\
Leptospira biflexa & Patoc & H & 2 \\
Turneria parva & Parva & $80-412$ & 1 \\
Leptonema illini & Illini & L 60 & 3 \\
Leptospira genomespécie 1 & Pingchang & Waz Holland (P438) & 2 \\
Leptospira genomespécie 2 & Manhao3 & LT 11-33 & 6 \\
Leptospira genomespécie 3 & Holland & são paulo & 1 \\
Leptospira genomespecie 4 & Hualin & São paulo & 1 \\
Leptospira genomespécie 5 & & & 1 \\
\hline
\end{tabular}

vel aos ácidos, perdendo sua motilidade em 15 minutos, quando em solução de $\mathrm{HCl}$ a 1:2000 (BRASIL, 1995).

\section{Epidemiologia e Clínica}

Os roedores das espécies Mus musculus, Rattus rattus, e principalmente o Rattus norvergicus, estão envolvidos na epidemiologia da leptospirose por eliminarem a leptospira por períodos prolongados. O homem é um hospedeiro acidental da leptospira, que se infecta quando em contato direto ou indireto com animais, e é susceptível a numerosos sorovares. Nas cidades, o rato de esgoto (Rattus norvergicus) é considerado o mais importante transmissor desta zoonose ao homem. Este roedor elimina pela urina por períodos prolongados, principalmente o sorovar icterohaemorrhagiae, causador da doença de Weil no homem. A leptospirose na zona urbana tem como característica marcante o aumento de sua incidência durante os períodos de grande pluviometria. A ratazana de esgoto elimina a leptospira por períodos prolongados, expondo milhares de pessoas ao risco de infecção quando da ocorrência de enchentes.

VASCONCELOS et al. (1992), na cidade de Londrina, Paraná, encontraram $28,4 \%$ de 208 soros humanos positivos, sendo maior a prevalência entre os trabalhadores da limpeza pública (46,7\%), do Departamento de Água e Esgotos $(24,1 \%)$, laboratoristas $(21,8 \%)$, estudantes e professores (10,2\%). ALMEIDA et al. (1994) obtiveram $10,4 \%$ sororeagentes, para diferentes sorovares.

TAVARES-NETO et al. (1996), em estudo na cidade de Uberaba, concluíram que o risco de contágio era maior para pessoas que tinham contato com animais como os trabalhadores de frigorífico, vaqueiros, estudantes de agrotécnica e trabalhadores de limpeza pública, sendo que a frequiência de sorologia positiva neste grupo foi de $46,7 \%$, mostrando os aspectos ocupacionais da enfermidade.

Nos bovinos a leptospirose é descrita tanto nas formas aguda, subaguda e crônica. As formas agudas e subagudas são mais observadas em animais jovens e em vacas em lactação, causando uma mastite atípica de início súbito com queda na produção leiteira. A forma crônica da doença é representada por distúrbios reprodutivos, principalmente abortos, que ocorrem com maior frequiência do $5 \underline{0}$ ao 60 mês de gestação. Os sorovares mais importantes nesta espécie são o hardjo e o pomona (SULLIVAN, 1974).

No Brasil, vários estudos foram realizados no sentido de verificar a frequiência de aglutininas anti-leptospíricas na espécie bovina. MOREIRA et al. (1979), realizando este estudo no Estado de Minas Gerais, encontraram $27,83 \%$ de amostras positivas, com maior incidência, para os sorovares wolffi, hardjo e pomona. Por sua vez, MADRUGA et al. (1980), na região sul do cerrado do Estado de Mato Grosso, obtiveram 74,5\% amos- 
tras positivas, sendo os sorovares mais encontrados o hardjo, sejroe, wolffi, australis e grippotyphosa. ABUCHAIM e DUTRA (1985) em Porto Alegre, acharam $49,8 \%$ de positividade, sendo os sorovares mais incidentes o pomona, hardjo e o sejroe.

VASCONCELLOS apud TEDESCO (1997), em pesquisa realizada com 2448 amostras de soro, provenientes de 56 propriedades de diferentes regiões do Brasil, obtiveram $61 \%$ de positividade. O sorovar hardjo foi o mais incidente, reforçando a sua importância nos diferentes estados. Para a mesma espécie, LANGONI et al. (1998a) obtiveram $45,56 \%$ de soropositividade entre as 2.761 amostras de soro examinadas, procedentes dos Estados de São Paulo e Paraná. Os sorovares mais prevalentes foram: wolffi $70,6 \%$, hardjo $67,6 \%$, pyrogenes $27,9 \%$, canicola $25,9 \%$, bratislava $23,0 \%$ e pomona $10,5 \%$.

Na espécie suína os transtornos reprodutivos proporcionados pela infecção leptospírica também são os principais sintomas, que consistem em retorno ao cio nas primeiras seis semanas de gestação, descargas vulvares, abortos na fase final da gestação, natimortos e nascimento de leitões fracos (OLIVEIRA, 1994). Os cachaços são carreadores de Leptospiras (ELLIS et al. 1986).

Em outros países os sorovares mais isolados a partir de suínos são o pomona e o bratislava. No Brasil, há registros de isolamento dos sorovares pomona, icterohaemorrhagiae e canicola (CASTRO et al., 1962; SANTA ROSA et al., 1962a,b). Um outro sorovar que tem assumido posição de destaque pela sua alta incidência na criação suína é o bratislava, sendo detectadas evidências de infecção por este sorovar no Brasil por OLIVEIRA et al. (1993). Este sorovar multiplica-se e persiste no trato genital de machos e fêmeas suínas (OLIVEIRA, 1994). LANGONI et al. (1995a), mostram o envolvimento de diferentes sorovares nesta espécie, com $27,3 \%$ de positividade, sendo o sorovar principal o icterohaemorraghiae, com $65,48 \%$ de amostras positivas.

Em ovinos é tida como de baixa freqüência, sendo estes considerados como hospedeiros acidentais. Entretanto, no Brasil, SANTA ROSA e CASTRO (1973) e VIEGAS et al. (1980), encontraram 34\% e $8 \%$ de positividade, respectivamente. LANGONI et al. (1995 b) observaram $44,65 \%$ de positividade dentre 356 amostras testadas, provenientes de 18 propriedades do Estado de São Paulo, com prevalência para os sorovares icterohaemorraghiae $(51,25 \%)$, castellonis $(20,62 \%)$, hardjo $(19,30 \%)$, bratislava $(16,25 \%)$, andamana e wolffi, com $11,88 \%$, entre outros menos freqüentes.

Nos cães, a leptospirose assume um caráter de doença aguda, cujos principais sorovares envolvidos são o canicola e icterohaemorrhagiae. Ambos podem le- var a quadros severos da doença com febre alta, icterícia, insuficiência renal, vasculite generalizada grave, lesão entérica entre outras. As principais fontes de infecção para esta espécie são principalmente outros cães infectados e os roedores. LANGONI et al. (1998b) obtiveram $23,6 \%$ e $19,0 \%$ de positividade para os sorovares canicola e icterohaemorraghiae, respectivamente, nesta espécie.

Para os bubalinos, são descritos sintomas como icterícia, febre e abortos (XU et al., 1983). No Brasil SANDOVAL et al. (1979) e GIORGI et al. (1981) encontraram $6,9 \%$ e $6,7 \%$ de positividade. YASUDA et al. (1982) encontraram $22,4 \%$ de prevalência, sendo os sorovares prevalentes o gryppotyphosa, pomona, wolffi e icterohaemorrhagiae. GIRIO et al. (1984) e LANGONI et al.(1997) observaram 15,75 e $37,7 \%$ de positividade.

Nos eqüinos há relatos de animais com mialgia, fraqueza, febre, abortos e de portadores (BERNARD et al., 1993). O resultado de inquérito sorológico com 1.133 amostras de soro procedentes de São Paulo, Goiás e Mato Grosso do Sul, realizado por LANGONI et al. (1998c), revelou positividade em 55,5\%, com prevalência para os sorovares icterohaemorraghiae $(59,7 \%)$, canicola $(64,8 \%)$ e pyrogenes $(59,7 \%)$, entre outros.

\section{Diagnóstico}

O diagnóstico da leptospirose deve se basear fundamentalmente nos achados clínicos, sorológicos, e na detecção e isolamento do agente. Pode-se suspeitar da doença em cães com hepatite, insuficiência renal, alterações entéricas, febre alta, anorexia, entre outros, associado a uma anamnese que conste histórico do animal que tenha acesso à rua e/ou a roedores, principalmente naqueles animais não vacinados. Em bovinos, a doença aguda não é freqüente, entretanto quadros de hemólise com hemoglobinúria, diminuição dos movimentos ruminais, anorexia, febre, principalmente nos animais jovens, são os sintomas mais freqüentes. Outro sinal clínico sugestivo é a mastite, que se caracteriza por aparecimento súbito, com presença de grumos amarelados ou sangue, com o úbere flácido à palpação, com considerável queda na produção leiteira.

O diagnóstico microbiológico é possível com o isolamento do agente a partir de secreções como urina e de fetos abortados, e ainda por técnicas de imunofluorescência. Outros métodos como coloração pela prata e microscopia de campo escuro têm sido utilizados para demonstrar as leptospiras em tecidos. Além de meios espe- 


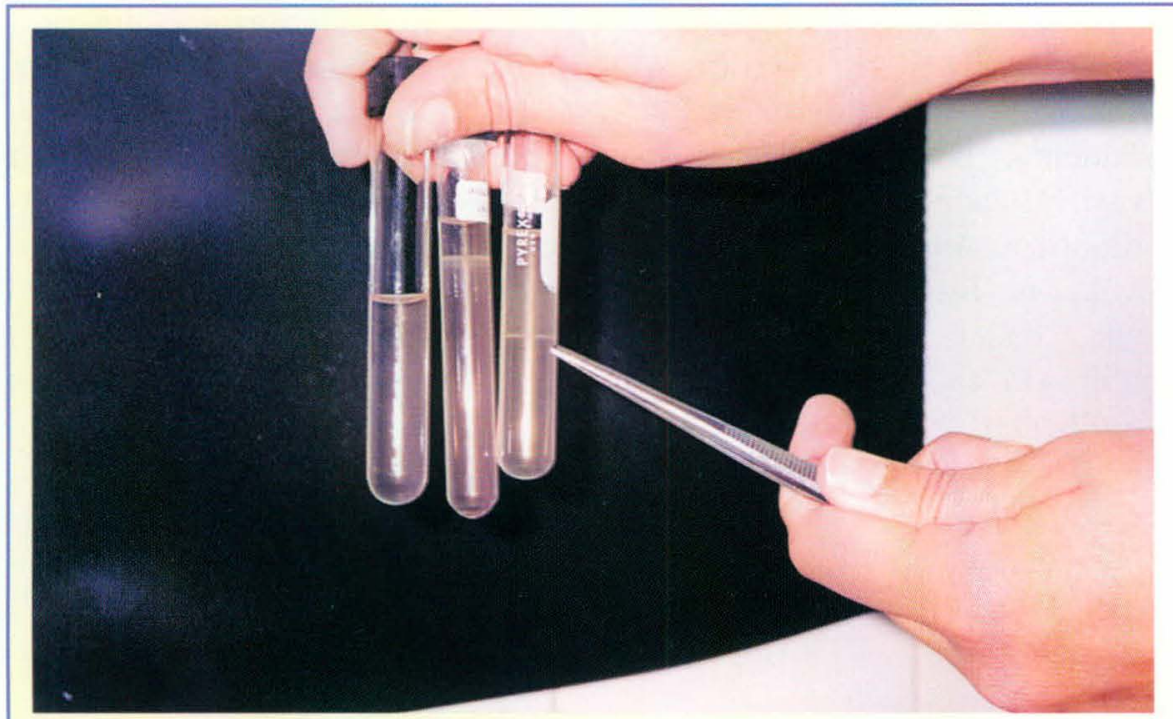

Foto 1 - Isolamento de leptospira em meio semi-sólido de Fletcher

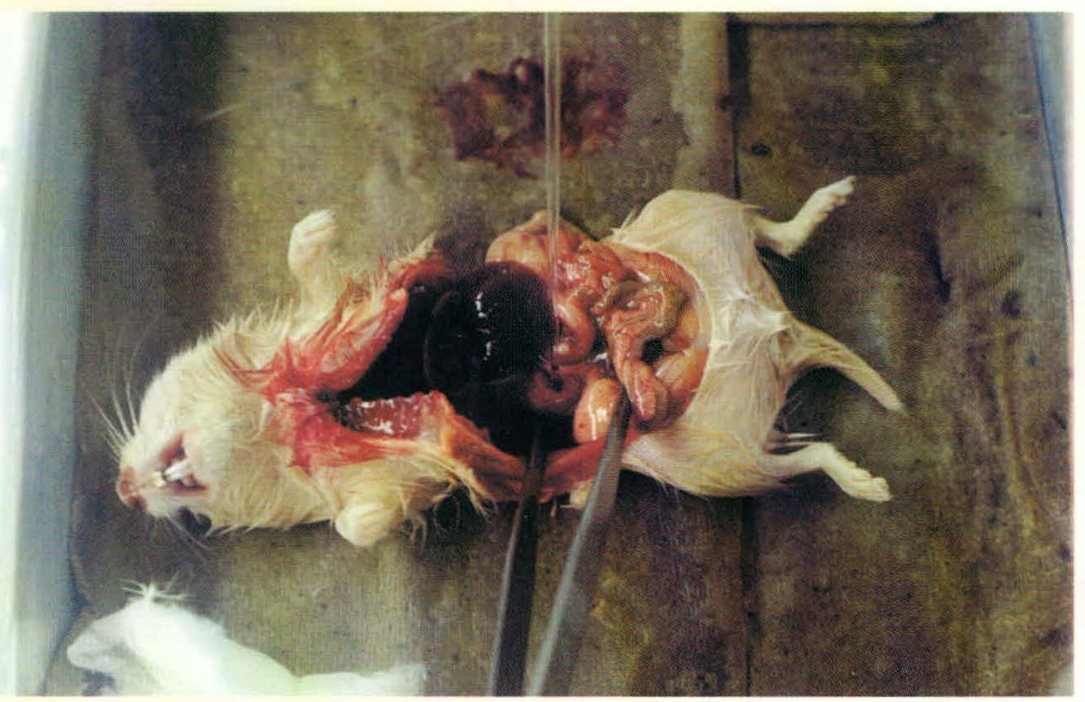

Foto 2 - Hamsters (Mesocricetus auratus). Colheita de material para isolamento de leptospira

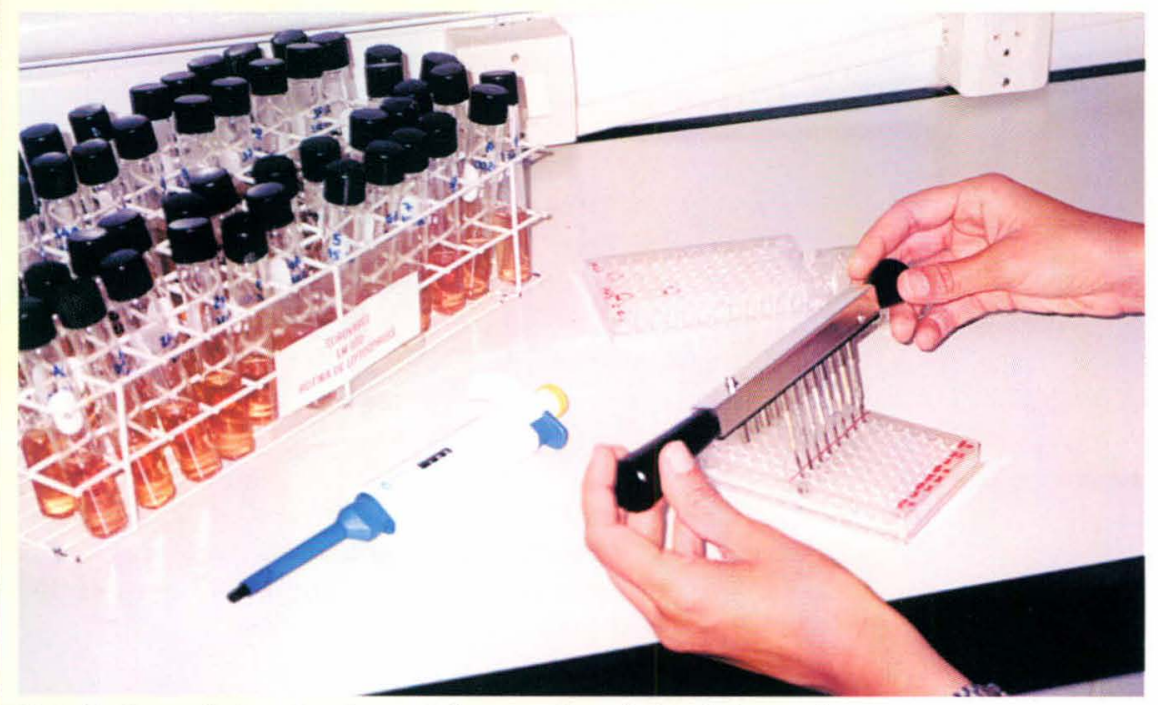

Foto 3 - Soroaglutinação microscópica para diagnóstico da leptospirose ciais para este fim (Foto 1), pode-se utilizar hamsters (Mesocricetus auratus), que é considerado como melhor modelo biológico para o seu isolamento (Foto 2).

O teste sorológico pela prova de soroaglutinação microscópica é o procedimento laboratorial mais difundido no diagnóstico da leptospirose (Foto 3). Para os quadros agudos da doença tem sua utilização limitada, uma vez que na primeira semana da doença não é possível a detecção de anticorpos (HARTMAN, 1977). São utilizados ainda os testes de ELISA, e SILVA et al. (1997) desenvolveram um DOTELISA para detecção de IgM contra os vários sorovares.

As técnicas de biologia molecular vieram preencher lacunas de sensibilidade e praticidade das outras provas diagnósticas utilizadas na pesquisa de leptospiras. O DNA, uma molécula muito estável, pode ser facilmente detectada mesmo em amostras autolisadas ou contaminadas, viabilizando o diagnóstico rápido e sensível, em muitos casos que outras provas seriam inviáveis. A análise de fragmentos de restrição permitiu a diferenciação de hardjo prajitno e hardjo bovis.

\section{Profilaxia}

A sua profilaxia deve se basear em ações que atuem diretamente sobre o animal, como a imunoprofilaxia, pela utilização de vacinas, como aquelas dirigidas para o controle de seus reservatórios, sejam os próprios animais infectados, bem como os roedores e o ambiente.

O combate aos roedores deve ser realizado com medidas estratégicas que maximizem os resultados de desratização e anti-ratização. Existem duas maneiras de combater os roedores: utilizandose de processos mecânicos ou físicos, como ratoeiras e armadilhas, 
que são eficientes para camundongos, colocandoas na trilha destes animais; e processos químicos, que são os raticidas, do tipo agudo e crônico.

Os agentes microbianos são fundamentais no controle e profilaxia da leptospirose. A variabilidade dos diferentes sorovares para os vários antibióticos são descritos nos diferentes trabalhos. Sendo assim, foram observadas alta susceptibilidade "in vitro" da leptospira para ampicilina, amoxicilina, penicilina $\mathrm{G}$, cefotaxime, eritromicina, tiamulin, mas resistência para cefalotina, cloranfenicol e sulfonamidas. Para os testes "in vivo" a ampicilina, cefotaxime, mexalactam, foram efetivas na eliminação das leptospiras dos rins. Entretanto, a dihidroestreptomicina surge como a melhor droga para este mister, o que se deve à combinação de sua ação bactericida e habilidade em persistir no tecido renal. Altas doses de tetraciclina podem eliminar a leptospira em animais de experimentação, entretanto a penicilina $\mathrm{G}$ não tem mostrado resultados favoráveis (PRESCOTT, 1991).

A vacinação contra leptospirose é a principal arma para se prevenir a infecção nos animais. As vacinas contendo o microrganismo morto ou inativado, são as mais usadas no controle das leptospiroses.

\section{SUMMARY}

Leptospirosis is a zoonotic disease with acute to cronic evolution, affecting domestic and wild animals, also cold-blooded species. The spirochetes from Leptospira genera are the aetiologic agent, found in environment, living a saprofhyte life too. It's an important public health concern, linked to socio-economical problems, flood, and occupacional exposure in slaughterhouse employees, water and agricultural activities. This paper gives informations abouts the leptospirosis agents, with the new classification, epidemiological aspects from susceptible species, with the disease prevalence. Are show pathological, diagnostic and clinical aspects, and the profilatic measurements.

Uniterms: Leptospirosis, Animal health, Public health

\section{BIBLIOGRAFIA DE APOIO}

1 - ABUCHAIM, D.M., DUTRA, N.L.F. Prevalência da leptospirose em bovinos da bacia leiteira de Porto Alegre - RS. Arq. Fac. Vet. UFRGS, v.13, p.55-60, 1985.

2 - ALMEIDA, L.P., MARTINS, L.F.S., BROD, C.S., GERMANO, P.M.L. Levantamento soroepidemiológico de leptospirose em trabalhadores do serviço de saneamento ambiental em localidade urbana da região sul do Brasil. Rev.Saúde Pública, v.28, p.76-81, 1994.

3 - BARANTON, G. DNA relatedness of serovars. Prepublication list. Unité de Bactériologie Moléculaire et Médicale, Institut Pasteur. Leptospira Molecular Biology Home Page (http: www. pasteur.fr/bio/leptospira). 1998.

4 - BERNARD, W.V.; BOLIN, C; RIDDLE, T., et al. Leptospiral abortion and leptospiruria in horses from the same farm. $\mathbf{J}$. Am. Vet. Med. Assoc., v.202, p.1285-6, 1993.

5 - BRASIL. MINISTÉRIO DA SAÚDE. Fundação Nacional de
Saúde. Centro Nacional de Epidemiologia. Coordenação de Controle de Zoonoses e Animais peçonhentos. Manual de Leptospirose. 2. ed. Ref. - Brasília: Fundação Nacional de Saúde, 1995, 98 p.

6 - CASTRO, A.F.P.; SANTA ROSA, C.A.; CALDAS, A.D. Isolamento de Leptospira canicola de suínos abatidos em matadouro. Arq. Inst. Biol., v.29, p.193-7, 1962.

7 - ELLIS, W.A., MCPARLAND, P.J., BRYSON, D.G., et al. Boars as carriers of leptospires of the Australis serogroup on farms with an abortion problem. Vet. Rec., v.17, p.563, 1986.

8 - GIORGI, W.; TERUYA, J.M., SILVA, A.S., et. al. Leptospirose: resultados das soro-aglutinações realizadas no Instituto Biológico de São Paulo, durante os anos de 1974/ 1980. Biológico, v.47, p.299-309, 1981.

9 - GIRIO, R.J.S., MATHIAS, L.A., YANAGUITA, R.M. Pesquisa de aglutininas anti-leptospira em soros de búfalos de qua- 
LANGONI, HELIO. Leptospirose: Aspectos de saúde animal e de saúde pública. Revista de Educação Continuada do CRMV-SP / Continuous Education Journal CRMV-SP. São Paulo, volume 2, fascículo 1, p. 52 - 58, 1999.

tro municípios do Estado de São Paulo, Brasil. In: ENCONTRO DE PESQUISAS VETERINÁRIAS, 1, 1984, Londrina. Resumos..., Londrina. 1984, p.65.

10 - HARTMAN, E.G. Leptospirosis. Tijdschr. Diergeneeskd., v.102, p.45-52, 1977.

11 - LANGONI, H., MARINHO; M., BALDINI, S., et al. Pesquisa de aglutininas antileptospíricas em soros de ovinos no Estado de São Paulo, Brasil, utilizando provas de macroaglutinação em placa e soroaglutinação microscópica. Rev. Bras. Med. Vet., v.17, p.264-8, 1995b.

12 - LANGONI, H., CABRAL, K.G., SILVA, A.V., BALDINI, S. Inquérito soroepidemiológico para leptospirose suína. In: CONGRESSO BRASILEIRO DE VETERINÁRIOS ESPECIALISTAS EM SUÍNOS, 7, 1995. Anais ... Blumenau, 1995 a, p.153.

13 - LANGONI, H. Epidemiological survey on anti-leptospiral agglutinins on buffaloes from Vale do Ribeira, São Paulo State (Brazil). In: World Buffalo Congress, 5, Casserta, Itália, Proceedings ..., 1997, p.622-5.

14. LANGONI, H.; MEIRELLES, L.R.; GOTTSCHALK, S.; CABRAL; K.G.; GIMENES-BOSCO; S.M., SILVA, A.V. Serological profile of bovine leptospirosis. In: CONGRESO PANAMERICANO DE CIÊNCIAS VETERINÁRIAS, 15, 1998, Proceedings ..., Santa Cruz, Bolívia, $1998 \mathrm{a}, \mathrm{p} .155$.

15 - LANGONI, H., GOTTSCHALK, S., MEIRELLES, L.R., GIMENES-BOSCO, S.M., SILVA, A.V., CABRAL, K.G. Survey on antileptospiric agglutinins in equine specie. In: CONGRESO PANAMERICANO DE CIÊNCIAS VETERINÁRIAS, 15, 1998, Proceedings ..., Santa Cruz, Bolívia, 1998c, p.202.

16 - LANGONI, H.; GOTTSCHALK, S.; MEIRELLES, L.P., SILVA, A.V.; GIMENES-BOSCO; S.M., TONIN, F.B. Serological behavior of canine leptospirosis. In: CONGRESO PANAMERICANO DE CIÊNCIAS VETERINÁRIAS, 15, 1998, Proceedings ..., Santa Cruz, Bolívia, 1998b, p.240.

17 - MADRUGA, C.R.; AYCARDI, E.; PUTT, N. Freqüência de aglutininas anti-leptospira em bovinos de corte da região sul de cerrado do Estado de Mato Grosso. Arq. Esc. Vet. UFMG, v.3, p. $245-49,1980$.

18 - MOREIRA, E.C. SILVA; J.A.; VIANA, F.C., et al. Leptospirose bovina: I-Aglutininas anti-leptopiras em soros sangüíneos de bovinos de Minas Gerais. Arq. Esc. Vet. UFMG, v.31, p.37588, 1979.

19 - OLIVEIRA, S.J. Atualização nos conceitos sobre leptospirose em suínos. Hora Vet., n.79, p.52-55, 1994.

20 - OLIVEIRA, S.J.; BOROWSKI, S.M.; BARCELLOS, BRASIL, D.E.S.N. Evidências de infecção por L.bratislava em casos de transtornos reprodutivos em suínos. In: CONGRESSO BRA-
SILEIRO DE VETERINÁRIOS ESPECIALISTAS EM SUÍNOS, 11, 1993, Goiânia. Proceedings..., Goiânia, 1993.

21 - PRESCOTT, J. Treatment of leptospirosis. Cornell Vet., v.81, p.7-12, 1991.

22 - QUINN, P.J.; CARTER, M.E.; MARKEY, B.; CARTER, G.R. Clinical veterinary microbiology. Spain: Grafos, 1994, p. 292-303.

23 - SANDOVAL, L.A.; ARRUDA, N.M.; TERUYA, J.M., et al. Pesquisas em bubalinos: prevalência de brucelose e leptospirose no Estado de São Paulo, Brasil. Biológico, v.45, p.209212, 1979.

24 - SANTA ROSA, C.A., CASTRO, A.F.P. Presença de aglutininas antileptospira em soro de ovinos e caprinos do Estado de São Paulo. Arq. Inst. Biol., v.30, p.93-8, 1973.

25 - SANTA ROSA, C.A., CASTRO, A.F.P., CALDAS, A.D. Isolamento de L.icterohaemorrhagiae e L.hyos de suínos abatidos em matadouro. Arq. Inst. Biol., v.29, p.285-92, 1962a

26 - SANTA ROSA, C.A., CASTRO, A.F.P., TROISE, C. Isolamento de L.pomona de suíno em S.Paulo. Arq. Inst. Biol., v.29, p.165-174, 1962b

27 - SILVA, M.V.; NAKAMURA, P.M.; CAMARGO, E.D.; BATISTA, L.; VAZ, A.J.; ROMERO, E.C., BRANDAO, A.P. Imunodiagnosis of human leptospirosis by Dot-Elisa for the detection of IgM, IgG and IgA antibodies. Am.J.Trop.Med.Hyg., v.56, p.650-5, 1997.

28 - SULLIVAN, N.D. Leptospirosis in animals and man. Austr. Vet. J., v.50, p.216-23, 1974.

29 - TAVARES-NETO, J., ANDRADE, J., HOFER, E., et al. Freqüência de aglutininas para leptospira observadas em habitantes de Uberaba, Minas Gerais. Rev. Soc. Bras. Med. Trop., v.29, p.55-8, 1996.

30 - TEDESCO, L.A. Leptospirose: uma doença que se expande e assusta. Balde Branco, n.9, p.44-48, 1997.

31 - VASCONCELOS, L.M.; CISALPINO, E.O.; VIEIRA, M.N.R.; KOURY, M.C. Pesquisa de aglutininas antileptospiricas em diferentes profissionais na cidade de Londrina, Paraná. Rev.Soc.Bras.Med.Trop., v.25, p.251-5, 1992.

32 - VIEGAS, E.; VIEGAS, S.A.R.; CALDAS, E.M. Aglutininas antileptospiras em hemossoros de caprinos e ovinos no Estado da Bahia. Arq. Esc. Med. Vet.. Univ. Fed. Bahia, v.5, p.2034, 1980.

33 - XU, J.T., PIAN, R.L., MAO, J.S., et al. A survey of leptospiral abortions in buffaloes. Chin. J. Vet. Med., v.9, p.19-20, 1983.

34 - YASUDA, P.H., SAMARA, S.I., PINTO, A.A. Aglutininas antileptospiras em búfalos. In: ENCONTRO DE PESQUISAS VETERINÁRIAS, 7, 1982, Jaboticabal. Resumos..., Jaboticabal. 1982, p.105-6. 


\section{AGRADECIMENTOS}

Aos Médicos Veterinários Aristeu Vieira da Silva e Kenio de Gouvea Cabral, pós-graduandos da Área de Vigilância Sanitária, pela realização da revisão bibliográfica.
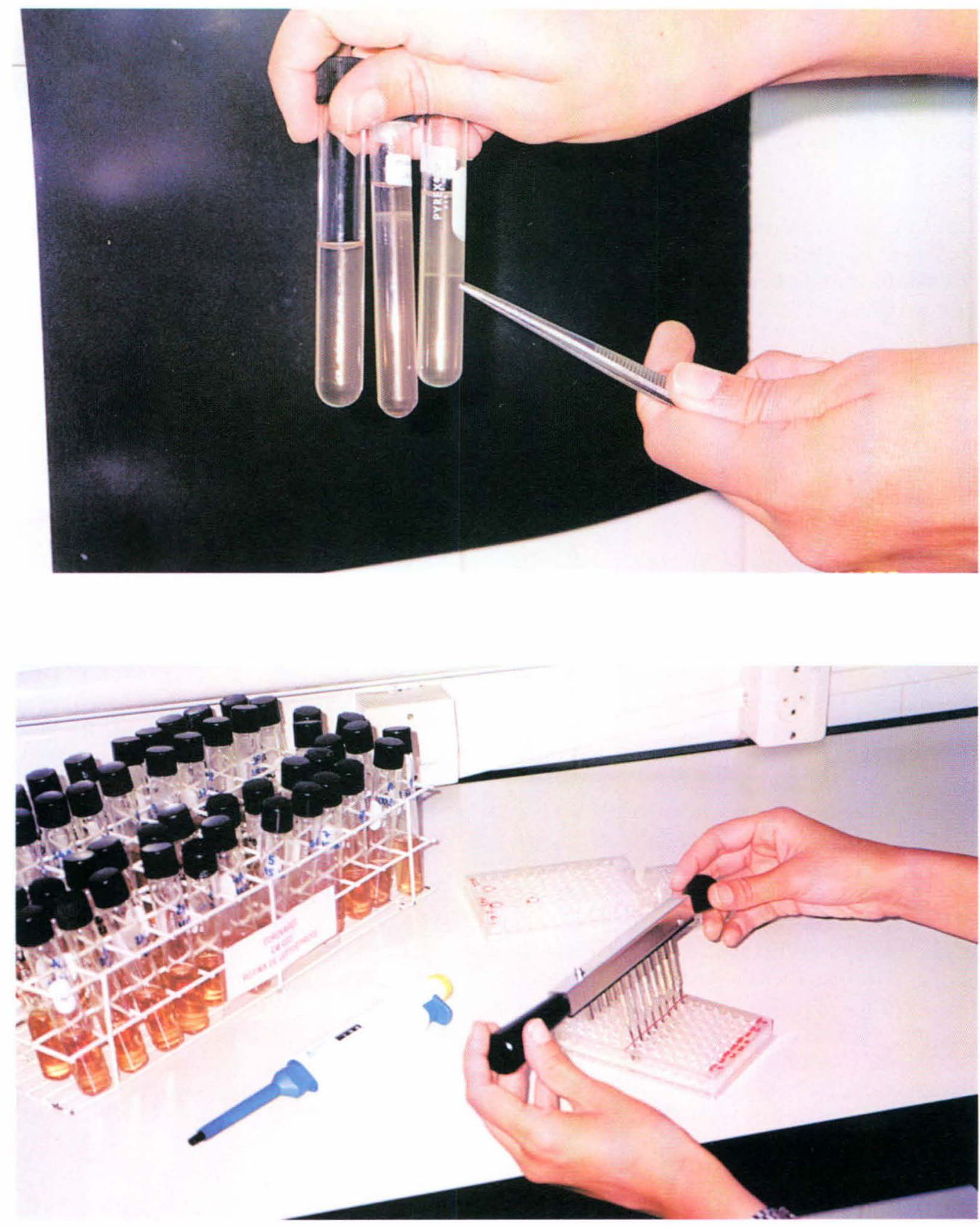